Article

\title{
Evidence for the Involvement of Toll-Like Receptor 4 (TLR4)-Mediated Apoptosis in Gynecological Cancers
}

\author{
Jinyoung Won ${ }^{1,2,3}$, Youngjeon Lee ${ }^{4}$, Kyu-Tae Chang 4,* and Yonggeun Hong 1,2,3, ** \\ 1 Department of Rehabilitation Science, Graduate School of Inje University, Gimhae 50834, Korea; \\ wy11167@naver.com \\ 2 U-Healthcare \& Anti-aging Research Center (u-HARC), Inje University, Gimhae 50834, Korea \\ 3 Biohealth Products Research Center (BPRC), Inje University, Gimhae 50834, Korea \\ 4 National Primate Research Center (NPRC), Korea Research Institute of Bioscience and Biotechnology \\ (KRIBB), Ochang 28116, Korea; neurosci@kribb.re.kr \\ 5 Department of Physical Therapy, College of Biomedical Science \& Engineering, Inje University, Gimhae \\ 50834, Korea \\ * Authors to whom correspondence should be addressed; E-Mails: yonghong@inje.ac.kr (Y.H.); \\ changkt@kribb.re.kr (K.-T.C.); Tel.: +82-55-320-3681 (Y.H.); +82-43-240-6322 (K.-T.C.); Fax.: +82-55-329-1678 \\ (Y.H.); +82-43-240-6309 (K.-T.C.).
}

\begin{abstract}
Toll-like receptor 4 (TLR4) is a member of the TLR family. Members of the TLR family play an important role in innate immune responses and are induced by recognition of pathogenassociated molecular patterns. They are also involved in cell proliferation and apoptosis in cancer. We investigated the role of TLR4 in apoptotic cell death in gynecological cancer cells; gynecological cancer is associated with infertility and spontaneous abortion. To examine the effect of TLR4 activation on apoptotic signaling in cancer cells, cultured primary cancer cells were treated with the TLR4 agonist lipopolysaccharide (LPS). The morphology of cancer cells was compared with normal myometrial cells. Enhanced growth rate and loss of contact inhibition with cellular overlap was observed in the cancer cells. The molecular mechanism analysis revealed differential expression of tumor suppressor genes in LPS-treated cancer cells. The expression of apoptosis-related caspase-3 was increased significantly in cancer cells with TLR4 activation after exposure to LPS. Taken together, these results suggest the pro-apoptotic activity of TLR4 as a potential therapeutic target for the treatment of gynecological cancers.
\end{abstract}

Keywords: apoptosis; gynecologic cancer; lipopolysaccharide; proliferation; Toll-like receptor

\section{Introduction}

Gynecological cancers, such as uterine cervix, endometrial, and ovarian cancers, cause serious morbidity and mortality. Moreover, they are common malignancies in women [1]. There are an estimated 1 million new cases of and 500,000 deaths due to gynecological cancers annually worldwide [2,3]. Of all gynecological cancers, uterine cervix cancer is a major cause of death in woman, after breast, endometrial, and ovarian cancer [4]. While gynecological cancer mortality has decreased due to improvements in cancer therapies, such as chemotherapy, radiation therapy, and surgery, additional research is needed for the development of therapeutic strategies to address the risks of infertility and spontaneous abortion [5].

Toll-like receptors (TLRs) play important roles in early innate immune defense mechanisms through recognition of pathogen-associated molecular patterns (PAMPs) [6]. TLRs 1-13 have been identified in human and mouse, which are evolutionarily conserved in terms of responses to specific classes of microbes [7]. Most TLRs have been found to trigger responses after recognition of PAMPs or microbe-associated molecular patterns (MAMPs). Damage-associated molecular patterns (DAMPs), produced by death signals, also stimulate TLR-dependent signal transduction [8]. The 
main function of the TLRs is to promote the innate immune response and trigger the adaptive immune response. Recent studies have reported that the activation of TLRs, induced by TLR agonists, promotes tumor-targeting immune responses effectively [9].

TLR-mediated immunotherapy is currently being investigated in the treatment of some cancers. In animal cancer models, the use of TLR agonists, such as TLR1/TLR2 agonists (e.g., bacterial lipoprotein; BLP), and TLR7/TLR8 agonists (e.g., imiquimod) has induced tumor regression [10,11]. Additionally, a TLR4 agonist (lipopolysaccharide; LPS) has shown anti-tumor effects via inhibition and delaying tumor growth [12].

Recent studies have reported the importance of TLR4 in tumor suppression pathways through induction of pro-inflammatory cytokine secretion [13]. Activation of TLR4, involved in apoptotic signaling, has been shown to protect against the development of cancer. TLR4 signaling is modulated via TLR adaptor protein which is composed of a toll/interleukin-1 receptor (TIR) domain. In TLR4 signaling, myeloid differentiation primary response gene 88 (MyD88)-dependent and TIR-domain containing adaptor inducing beta interferon (TRIF)-dependent pathways are essential for activation of transcription factor, nuclear factor kappa B (NF- $\kappa B$ ). Activation of TLR4-induced NF- $\kappa B$ then triggers multiple signal pathways, including those involved in immunity, inflammation, apoptosis, proliferation, and stress responses [14].

In this study, we established primary cultured cells from gynecological cancers and normal myometrium tissue to examine the morphology of cancerous and normal cells. We also investigated the role of TLR4 in apoptotic cell signaling in cancer to assess whether the molecular mechanism of TLR4-induced apoptosis might provide therapeutic target(s) for cancer treatment.

\section{Results}

\subsection{Isolation and characterization of primary cells from gynecological cancers}

Uterine cervix, endometrial, and ovarian cancers are the most lethal gynecological malignancies in woman. Cancerous tissues were obtained from patients at Paik Hospital; we isolated and cultured primary uterine cervix, endometrial, and ovarian cancer cells after collagenase type II treatment (Figure 1A). Morphological characterizations of primary cultured cells were made with an inverted microscope $\sim 6 \mathrm{~d}$ after culture initiation. Colonies of cancer cells attached and started to spread, with cell proliferation (Figure 1B). The density of gynecological cancer cells reached 100\% confluency more rapidly than did the normal cells (data not shown). 
A
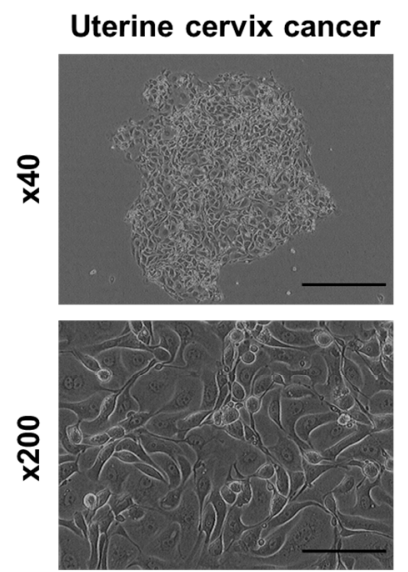

B
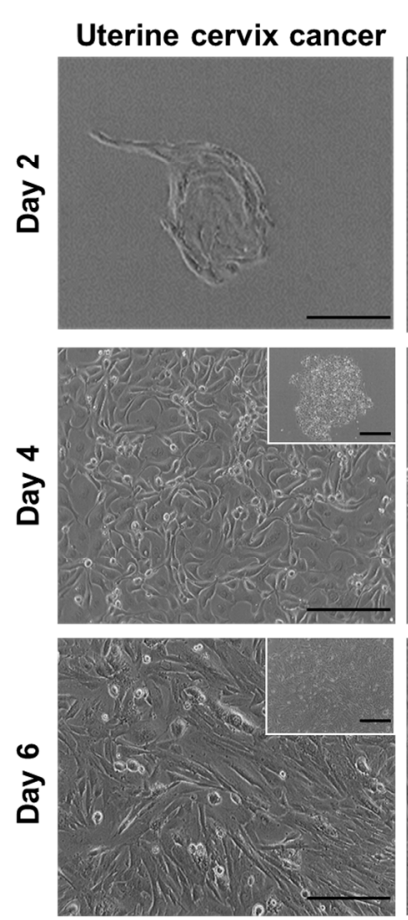
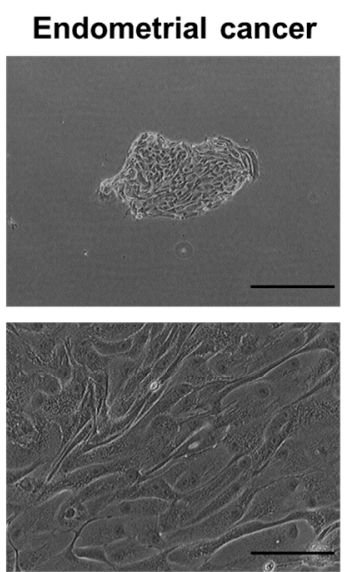

Endometrial cancer


Ovarian cancer

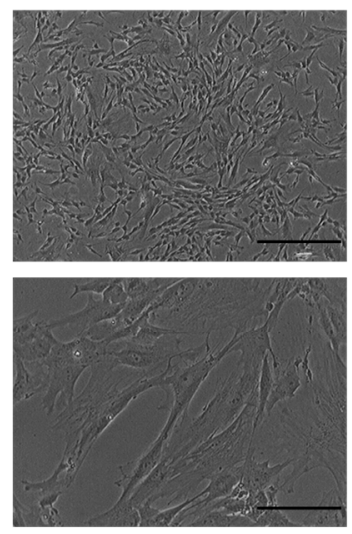

Ovarian cancer
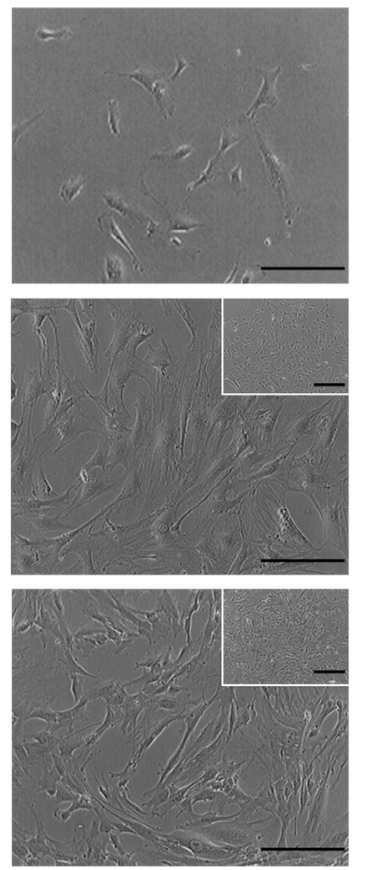

Figure 1. Primary cultures of gynecological cancer cells. (A) Primary cells were isolated from gynecological cancer tissues, supplied by Paik Hospital. Scale bars $=500 \mu \mathrm{m}(40 \times), 100 \mu \mathrm{m}(200 \times)$. (B) Comparison of morphological characterization of primary culture gynecological cancer cells, including uterine cervix, endometrial, and ovarian cancer cells. Scale bars $=500 \mu \mathrm{m}(40 \times), 200 \mu \mathrm{m}$ $(100 \times)$.

\subsection{Analysis of the cell growth curve and proliferation of uterine cervix cancer cells}

Primary cultured cells were observed to assess cell proliferation after initial seeding (at $5 \times$ $10^{4} / \mathrm{mL}$ ). Uterine cervix cancer cells showed active proliferation and loss of contact inhibition, with cellular overlap occurring within $72 \mathrm{~h}$ (Figure 2A). While the cancer cells rapidly reached high confluency within $72 \mathrm{~h}$, normal cells showed a largely constant basal density level of $<50 \%$ until Day 7.

To confirm the growth curve and proliferation of normal versus cancer cells, cell counting was performed with a hemocytometer every $24 \mathrm{~h}$. The cell doubling time was calculated from the following formula: $N=N O \times 2 t / T$, where $N O$ is the initial concentration of cells, $N$ is the final concentration of cells, $t$ is the duration of the culture, and $T$ is the doubling time. Uterine cervix cancer cells showed more rapid growth than normal myometrial cells over $7 \mathrm{~d}$. The cell doubling times of uterine cervix cancer and normal myometrial cells were $16.6 \mathrm{~h}$ and $26 \mathrm{~h}$, respectively (Figure 2B). 
A
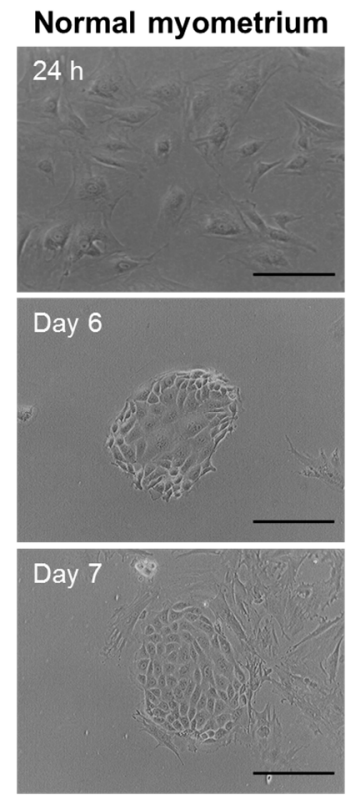
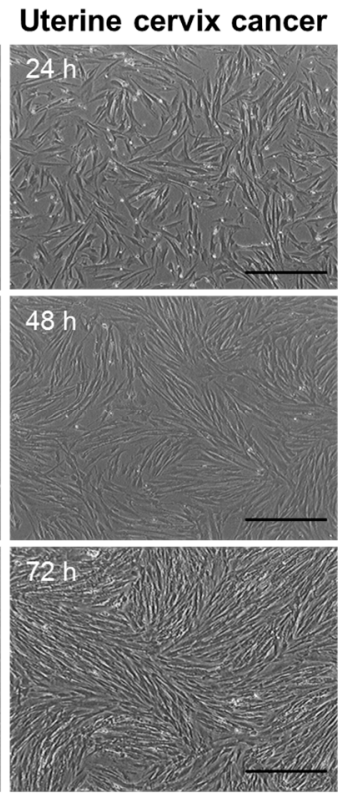

B

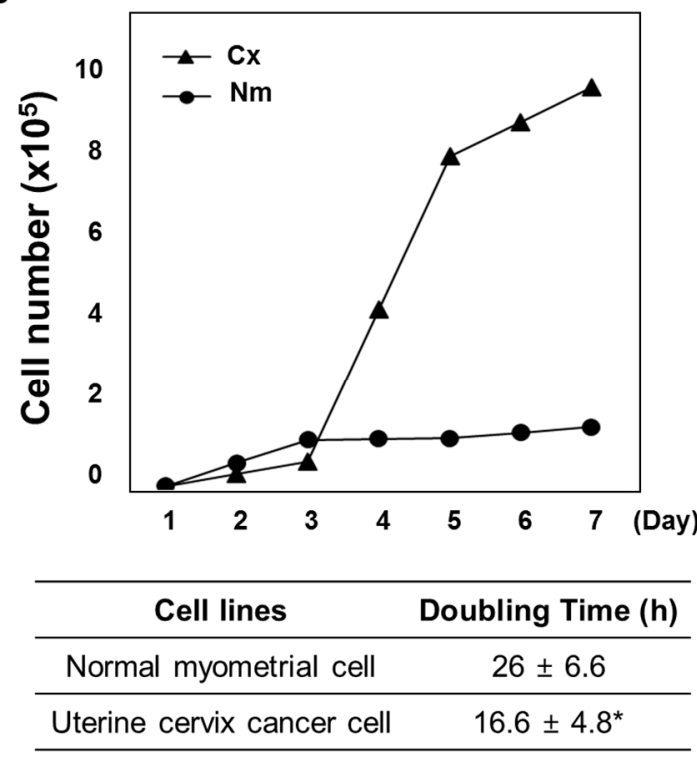

Figure 2. Cell growth curves and doubling times of primary culture cells. (A) Uterine cervix cancer cells and normal myometrial cells were assessed with an inverted microscope. Imaging of cancer cells revealed active proliferation, as compared with normal cells. Scale bars $=200 \mu \mathrm{m}(100 \times)$. (B) Doubling times and cell numbers were measured to assess cell proliferation. Nm, normal myometrial cells; $\mathrm{Cx}$, uterine cervix cancer cells. ${ }^{*} P<0.05$ vs. normal myometrial cells.

\subsection{Effects of LPS-induced TLR4 activation on gene expression in uterine cervix cancer cells}

To determine changes in gene expression in normal and cancerous cells, RT-PCR analysis was performed for the integrin alpha 5 (ITGA5), p53, toll-like receptor 4 (TLR4), senescence marker protein 30 (SMP30), and glyceraldehyde 3-phosphate dehydrogenase (GAPDH) genes using total RNA samples isolated from cultured primary cells (Figure 3A). The expression of ITGA5, an alpha5 integrin marker, was upregulated in myometrial cells but not in uterine cervix cancer cells. Expression of ITGA5 was observed primarily in smooth muscle, including myometrium and endometrium tissues. Additionally, expression of SMP30, a senescence marker, was seen in normal cells but not in cancer cells. However, the expression of $p 53$, related to tumor suppression, was increased in cancerous versus normal cells.

To examine the effects of LPS-mediated TLR4 activation on apoptotic signaling in cancer, uterine cervix cancer cells $\left(5 \times 10^{5} / \mathrm{mL}\right)$ were stimulated with LPS $(1 \mu \mathrm{g} / \mathrm{mL})$ or vehicle in DMEM containing $10 \% \mathrm{FBS}$ and penicillin/streptomycin $(60 \mu \mathrm{g} / \mathrm{mL})$. Factors associated with tumor suppression were differentially expressed after LPS treatment (Figure 3B). Increased TLR4 expression was observed in LPS-treated cancer cells. Additionally, gene expression of caspase-3, involved in apoptotic cell death, was increased after LPS treatment versus treatment with vehicle. These results indicated that the activation of TLR4, mediated by LPS, was associated with the caspase-dependent apoptotic pathway. 
A
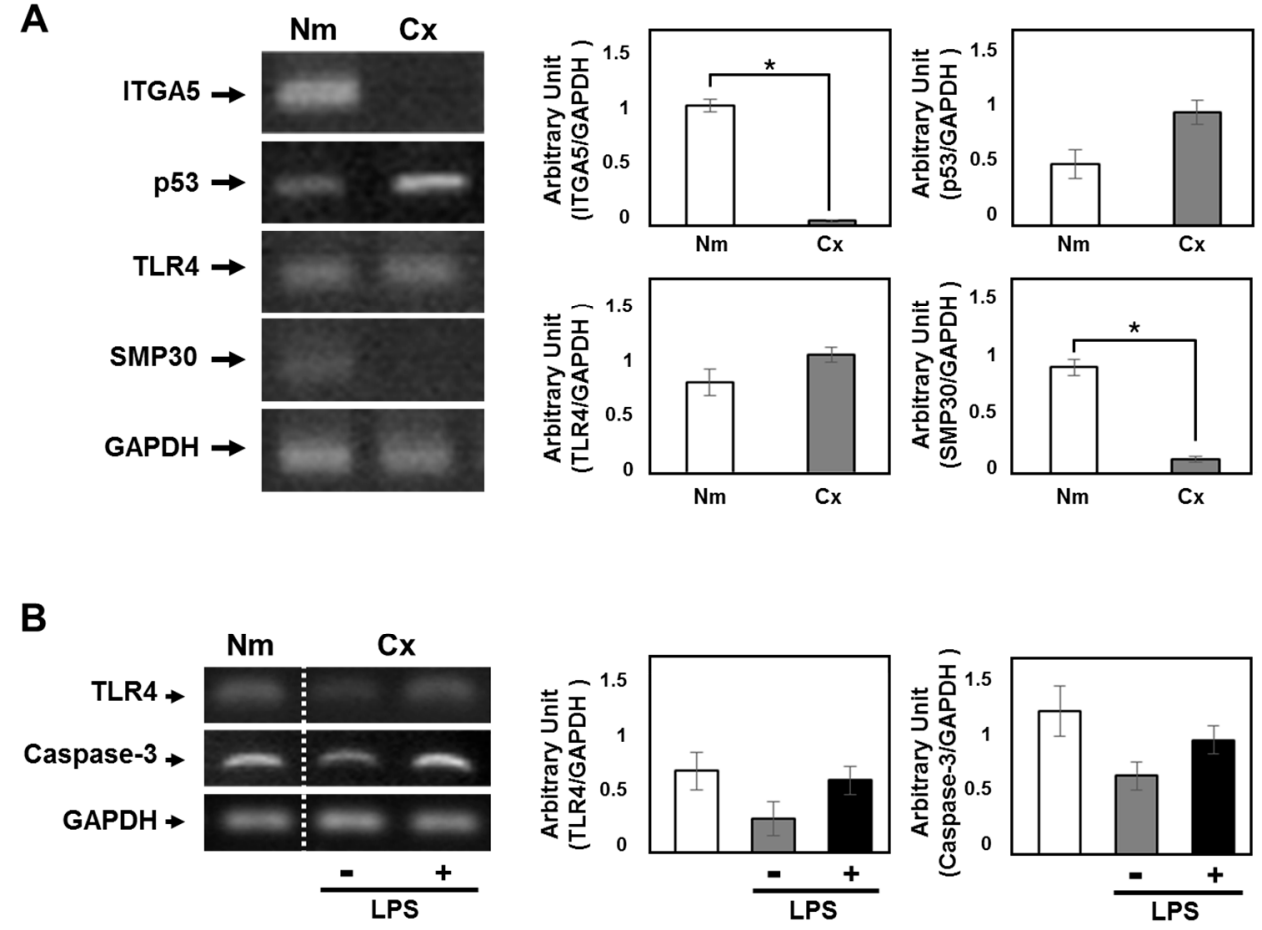

Figure 3. Comparison of the gene expression patterns of normal cells and cervical cancer cells. (A) Reverse transcription polymerase chain reaction (RT-PCR) analysis of the integrin alpha 5 (ITGA5), p53, toll-like receptor 4 (TLR4), senescence marker protein 30 (SMP30), and glyceraldehyde 3phosphate dehydrogenase (GAPDH) genes using total RNA samples isolated from cultured primary cells. Nm, normal myometrial cells; Cx, uterine cervix cancer cells. (B) RT-PCR analysis of the TLR4, caspase-3, and GAPDH genes using total RNA samples isolated from cultured primary cells. Uterine cervix cancer cells were stimulated with lipopolysaccharide (LPS). ${ }^{*} P<0.05$ vs. normal myometrial cells.

\section{Discussion}

The diagnosis and treatment of cancer have been revolutionized by recent developments in medicine. Molecular-based targeted therapy is currently under investigation as a potential therapeutic approach in the treatment of cancer. Cancer-specific genes, known as oncogenes, are activated in different cancers [15]. Additionally, genetic variations, including dysfunction of tumor suppressor genes, also increase the risk of some cancers [16]. A major hallmark of cancer is resistance to apoptotic cell death induced by activation of oncogenic signaling pathways [17]. This also has the potential to trigger certain normal cells to become cancerous, which is then associated with inappropriate proliferation and metastatic spread of cancer cells.

Several recent studies have reported on distinctive clinical and pathological features of gynecological cancers. Most gynecological cancers show metastatic tendencies and a progressive malignant state. Gene-based comparative analyses are currently being conducted in gynecological cancer research, but gene expression profiling has mostly failed to specifically characterize gynecological cancers, likely due to their diversity [18-20].

In this study, we established primary cultures using cancer biopsy specimens originating from female reproductive organs, including the uterine cervix, endometrium, and ovaries. Small clusters from cancer specimens were observed within 12-24 h after primary culture initiation. Colonies of cancer cells attached and spread within 3-4 d after initial seeding. In normal cells, cell viability and adhesion were similar to that of cancer cells. However, cancer cells displayed higher cell densities with limited contact inhibition [21]. Because many cancer cells are not sensitive to extracellular 
growth factors, they are largely unaffected by density-dependent inhibition [22]. Most normal cells, unlike cancer cells, stop proliferating and initiate cell cycle arrest before reaching confluence [23].

We identified characteristic doubling times and growth rates in gynecological cancer cells. Uncontrolled growth and proliferation occur commonly in cancers when the cells reach confluence. However, the growth of normal cells is arrested upon contact with each other. Previous studies have reported that the cell density at which normal cells stop proliferating is influenced by growth factor requirements [24]. Because of the loss of growth factor requirements in cancer cells, they can continue to proliferate independent of cell confluency [25]. Moreover, some cancer cells produce growth factors by autocrine mechanisms, stimulating cell division [26].

We compared gene expression patterns of normal myometrial cells with those of cervical cancer cells using RT-PCR. While the expression of $p 53$ and TLR4, related to tumor suppression, was increased, the expression of SMP30, related to senescence, was downregulated in cancerous versus normal cells. Other studies have reported that the expression of $p 53$ with mutations is commonly increased in human cancers [27]. SMP30 plays a role in cellular homeostasis and has protective effects against age-associated cell death [28].

We used cultured primary cancer cells to define apoptotic cell death, mediated by TLR4 activation. Expression of caspase-3, a specific cysteine protease, was upregulated, through LPSmediated TLR4 activation. The presence of caspase- 3 indicates the induction of apoptotic irreversible cell death. Therefore, these findings suggest that TLR4 activation, by LPS, induced apoptosis in cancerous cells. The present study provides evidence for the involvement of TLR4-mediated apoptosis in gynecological cancers. These results suggest that TLR agonists may be useful as potential anti-cancer agents. Further studies should focus on the role of TLR signaling in cancers, in association with the induction of immunotherapy.

\section{Materials and methods}

\subsection{Animals}

Animal study was approved by the Institutional Animal Care and Use Committee (IACUC). All experimental procedures using animals were conducted in accordance with the Inje University Animal Care guidelines and the Korean Department of Agriculture. Male Sprague-Dawley (SD) rats weighing 250-300 g (10-week-old) were maintained under a $12 \mathrm{~h} \mathrm{light/dark} \mathrm{cycle} \mathrm{with} \mathrm{free} \mathrm{access} \mathrm{to}$ laboratory chow and drinking water.

\subsection{Cell culture}

Primary cultured cells were maintained in Dulbecco's modified Eagle's medium (DMEM; Lonza, Walkersville, MD, USA), supplemented with 10\% fetal bovine serum (FBS; HyClone, Logan, UT, USA) and penicillin/streptomycin $\left(60 \mu \mathrm{g} / \mathrm{mL}\right.$; Lonza). Cultured cells were incubated at $37^{\circ} \mathrm{C}$ in a humidified atmosphere of $5 \% \mathrm{CO}_{2}$, and the culture medium was refreshed 2 or 3 times per week.

\subsection{Primary culture system}

Primary cancer cells were isolated from patients with gynecological malignancies. This procedure was approved by our institutional ethics committee. Gynecological cancer tissues, including uterine cervix, endometrial, and ovarian cancers, were obtained from patients with gynecologic conditions being treated at Paik Hospital. The average age of the patients was 45.3 years. These samples were minced into $1 \mathrm{~mm}^{3}$ pieces in Roswell Park Memorial Institute 1640 medium (RPMI 1640 medium; Lonza) using sterilized micro-scissors. The minced tissue was placed in a conical tube containing RPMI 1640 and $2 \mathrm{mg} / \mathrm{mL}$ collagenase type II, and incubated at room temperature for $15 \mathrm{~min}$ in a shaking incubator. After digestion, the cancer tissues were centrifuged at low speed (600-800 rpm, $3 \mathrm{~min}$ ) and the supernatant was removed. The cancer tissues were then subjected to further digestion with $0.025 \%$ trypsin- $0.02 \%$ ethylenediaminetetraacetic acid (EDTA) at room temperature for $10 \mathrm{~min}$ in a shaking incubator. Digestion was stopped by washing the tissue 3 
times with RPMI 1640. Gynecological cancer cells were maintained in RPMI 1640 supplemented with $10 \%$ FBS, penicillin $(60 \mu \mathrm{g} / \mathrm{mL})$, and streptomycin sulfate $(100 \mu \mathrm{g} / \mathrm{mL})$.

Myometrial cells isolated from uterine myometrial smooth muscle were used as 'normal' cells. Normal myometrial smooth muscle was obtained from female SD rats (10-week-old, weighing 250$300 \mathrm{~g}$ ). Rat uterine tissue was obtained and placed in a sterile Petri dish containing cold DMEM. Uterine tissue was separated from the uterine horn to the uterine cervix, and minced in DMEM into $1-\mathrm{mm}^{3}$ pieces using sterilized micro-scissors. The minced tissue was placed in a conical tube containing DMEM and $2 \mathrm{mg} / \mathrm{mL}$ collagenase type II at room temperature for $30 \mathrm{~min}$ in a shaking incubator. After digestion, the myometrial tissue was centrifuged at low speed (600-800 rpm, $3 \mathrm{~min}$ ) and the supernatant was removed. Myometrial cells were immersed in $0.025 \%$ trypsin- $0.02 \%$ EDTA (room temperature, $20 \mathrm{~min}$, shaking incubator). Myometrial cells were then collected by low-speed centrifugation (600-800 rpm, $3 \mathrm{~min}$ ), and washed 3 times with DMEM. Cultured primary myometrial cells were maintained in DMEM containing $10 \%$ FBS, penicillin $(60 \mu \mathrm{g} / \mathrm{mL})$, and streptomycin sulfate $(100 \mu \mathrm{g} / \mathrm{mL})[29,30]$.

\subsection{Cell proliferation assay}

To assess the growth curve of normal myometrial cells and uterine cervix cancer cells, cell counting was performed with a hemocytometer (Marienfeld Laboratory Glassware, LaudaKönigshofen, Germany). Cells were plated at $4 \times 10^{4}$ cells per $100 \mathrm{~mm}$ plate and incubated for $72 \mathrm{~h}$. Cell pellets were collected and resuspended in DMEM. Cells were stained with an equal volume of $0.4 \%$ trypan blue solution (Sigma-Aldrich) to determine the number of dead cells. Cells were counted with the hemocytometer every $24 \mathrm{~h}$, trypan blue-excluding and -positive cells.

\subsection{Chemical treatment}

Cells $\left(5 \times 10^{5} / \mathrm{mL}\right)$ were stimulated with $1 \mu \mathrm{g} / \mathrm{mL}$ LPS. Additionally, the cells were subjected to pretreatment with either vehicle or LPS in DMEM containing 10\% FBS and penicillin/streptomycin $(60 \mu \mathrm{g} / \mathrm{mL})$. Cell culture medium that contained vehicle or LPS was preincubated at $37^{\circ} \mathrm{C}$ in $5 \% \mathrm{CO}_{2}$.

\subsection{RNA isolation and reverse transcription polymerase chain reaction (RT-PCR) analysis}

RNA isolation was performed using the TRIzol ${ }^{\circledR}$ reagent (Sigma-Aldrich); total RNA was extracted according to the manufacturer's protocol. The concentration of RNA was determined with a spectrophotometer (Mecasys, Daejeon, Korea). RNA ( $5 \mu \mathrm{g})$ was reverse-transcribed using reverse transcriptase (Invitrogen, Carlsbad, CA, USA). The primers used are listed in Table 1. RT-PCR was performed using standard reaction conditions. PCR was conducted in the following steps: denaturation at $95^{\circ} \mathrm{C}$ for $30 \mathrm{~s}$, annealing at $60^{\circ} \mathrm{C}$ for $1 \mathrm{~min}$, and elongation at $72^{\circ} \mathrm{C}$ for $1 \mathrm{~min}$. Up to 40 PCR cycles were performed. The reaction mixture consisted of $0.5 \mu \mathrm{M}$ of the forward and reverse primers, $1.5 \mathrm{mM} \mathrm{MgCl}_{2}, 0.2 \mathrm{mM}$ of each deoxynucleotide (dNTP), and $1.25 \mathrm{U}$ of GoTaq ${ }^{\circledR}$ polymerase (Promega, Fitchburg, WI, USA). After amplification, the PCR products were electrophoresed on a $1.2 \%$ agarose gel and stained with ethidium bromide. The intensities of the amplified bands were quantified with the Gel Doc System and Quantity One ${ }^{\circledR}$ software (Bio-Rad Laboratories, Richmond, CA, USA). The ImageJ program was used to quantify the density (ver. 1.6; NIH, Bethesda, MD, USA).

Table 1. Sequence-specific primers used for RT-PCR.

\begin{tabular}{cccc}
\hline \hline Gene & Primer sequence (5'-3') & Product length(bp) GenBank accession No. \\
\hline \multirow{2}{*}{ SMP30 } & F: GGAGGCTATGTTGCCACCATTGGAAC & 560 & NM_031546 \\
& R: TTCCCTCCAAAGCAGCATGAAGTTGTTTTA & & \\
TLR4 & F: CATTCCTTTAAGTTGCCTGA & 200 & NM_019178 \\
R53 & R: ATATTTGCCAAGCAATTGAG & & \\
& F: CCGCGCCATGGCCATCT & 100 & NM_030989
\end{tabular}




\section{R: GCGCTCATGGTGGGGG}

ITGA5

Gapdh

\section{F: GGAAGGGACGGAGTCAGTGT}

R: ACTGGATAGGACTGGTGCCC

F: GGGTCATGGTTCATCCAGTC

R: GTCCAGGGAGAAGGACTCAA

F: GTATGACTCCACTCACGGCAAA

R: GGTCTCGCTCCTGGAAGATG
100
NM_012922

NM_001108118

BC094037

\subsection{Statistical analysis}

Data were subjected to statistical analyses using Student's $t$-tests or a one-way analysis of variance (ANOVA) followed by post hoc Tukey tests. Data are presented as means \pm standard deviation (SD). A $P$ value $<0.05$ was considered to indicate statistical significance.

Acknowledgments: This study was supported by the KRIBB Research Initiative Program (KGM4611613 to Y. Hong) and by the National Research Foundation (NRF-2013R1A2A2A01067169 to Y. Hong), Republic of Korea.

Conflicts of Interest: The authors declare no conflict of interest.

\section{References}

1. Suh, D.H.; Kim, M.; Kim, H.J.; Lee, K.H.; Kim, J.W. Major clinical research advances in gynecologic cancer in 2015. J Gynecol Oncol. 2016, 27, doi: 10.3802/jgo.2016.27.e53.

2. Minig, L.; Padilla-Iserte, P.; Zorrero, C. The Relevance of Gynecologic Oncologists to Provide High-Quality of Care to Women with Gynecological Cancer. Front Oncol. 2016, 5, 308.

3. Preedy, V.R.; Watson, R.R. Handbook of Disease Burdens and Quality of Life Measures, 2010th ed.; Springer: New York, USA, 2010; pp. 803-823.

4. Fitzmaurice, C.; Dicker, D.; Pain, A.; Hamavid, H.; Moradi-Lakeh, M.; MacIntyre, M.F.; Allen, C.; Hansen, G.; Woodbrook, R.; Wolfe, C.; et al. The global burden of cancer 2013. JAMA Oncol. 2015, 1, 505-527.

5. Fitzmaurice, C.; Dicker, D.; Pain, A.; Hamavid, H.; Moradi-Lakeh, M.; MacIntyre, M.F.; Allen, C.; Hansen, G.; Woodbrook, R.; Wolfe, C.; et al. The global burden of cancer 2013. JAMA Oncol. 2015, 1, 505-527.

6. Tan, R.S.; Ho, B.; Leung, B.P.; Ding, J.L. TLR cross-talk confers specificity to innate immunity. Int Rev Immunol. 2014, 33, 443-453.

7. Fukata, M.; Chen, A.; Klepper, A.; Krishnareddy, S.; Vamadevan, A.S.; Thomas, L.S.; Xu, R.; Inoue, H.; Arditi, M.; Dannenberg, A.J.; et al. Cox-2 is regulated by Toll-like receptor-4 (TLR4) signaling: Role in proliferation and apoptosis in the intestine. Gastroenterology. 2006, 131, 862-877.

8. Piccinini, A.M.; Midwood, K.S. DAMPening inflammation by modulating TLR signalling. Mediators Inflamm. 2010, 2010, doi: 10.1155/2010/672395.

9. Iribarren, K.; Bloy, N.; Buqué, A.; Cremer, I.; Eggermont, A.; Fridman, W.H.; Fucikova, J.; Galon, J.; Špíšek, R.; Zitvogel, L.; et al. Trial Watch: Immunostimulation with Toll-like receptor agonists in cancer therapy. Oncoimmunology. 2015, 5, e1088631.

10. Smits, E.L.; Ponsaerts, P.; Berneman, Z.N.; Van Tendeloo, V.F. The use of TLR7 and TLR8 ligands for the enhancement of cancer immunotherapy. Oncologist. 2008, 13, 859-875.

11. Zhang, Y.; Luo, F.; Li, A.; Qian, J.; Yao, Z.; Feng, X.; Chu, Y. Systemic injection of TLR1/2 agonist improves adoptive antigen-specific $T$ cell therapy in glioma-bearing mice. Clin Immunol. 2014, 154, 26-36.

12. He, W.; Liu, Q.; Wang, L.; Chen, W.; Li, N.; Cao, X. TLR4 signaling promotes immune escape of human lung cancer cells by inducing immunosuppressive cytokines and apoptosis resistance. Mol Immunol. 2007, 44, 2850-2859.

13. Janeway, C.A., Jr.; Medzhitov, R. Innate immune recognition. Annu Rev Immunol. 2002, 20, 197-216.

14. Kawai, T; Akira, S. Signaling to NF-kappaB by Toll-like receptors. Trends Mol Med. 2007, 13, 460-469.

15. Fleck, J.L.; Pavel, A.B.; Cassandras, C.G. Integrating mutation and gene expression cross-sectional data to infer cancer progression. BMC Syst Biol. 2016, 10, doi: 10.1186/s12918-016-0255-6.

16. Liu, Y.; Hu, X.; Han, C.; Wang, L.; Zhang, X.; He, X.; Lu, X. Targeting tumor suppressor genes for cancer therapy. Bioessays. 2015, 37, 1277-1286. 
17. Fulda, S. Regulation of cell death in cancer-possible implications for immunotherapy. Front Oncol. 2013, 3, doi: 10.3389/fonc.2013.00029.

18. Biewenga, P.; Buist, M.R.; Moerland, P.D.; Ver Loren van Themaat, E.; van Kampen, A.H.; ten Kate, F.J.; Baas, F. Gene expression in early stage cervical cancer. Gynecol Oncol. 2008, 108, 520-526.

19. Iguchi, Y.; Ito, Y.M.; Kataoka, F.; Nomura, H.; Tanaka, H.; Chiyoda, T.; Hashimoto, S.; Nishimura, S.; Takano, M.; Yamagami, W.; et al. Simultaneous analysis of the gene expression profiles of cancer and stromal cells in endometrial cancer. Genes Chromosomes Cancer. 2014, 53, 725-737.

20. Yin, J.G.; Liu, X.Y.; Wang, B.; Wang, D.Y.; Wei, M.; Fang, H.; Xiang, M. Gene expression profiling analysis of ovarian cancer. Oncol Lett. 2016, 12, 405-412.

21. Hanahan, D.; Weinberg, R.A. Hallmarks of cancer: the next generation. Cell. 2011, 144, 646-674.

22. Tyson, J.J.; Novak, B. Control of cell growth, division and death: information processing in living cells. Interface Focus. 2014, 4, doi: 10.1098/rsfs.2013.0070.

23. Alberts, B.; Johnson, A.; Lewis, J.; Raff, M.; Roberts, K.; Walter, P. The Cell Cycle and Programmed Cell Death. Molecular Biology of the Cell, 4th ed.; Garland Science: New York, USA, 2002; https://www.ncbi.nlm.nih.gov/books/NBK26877/

24. Goustin, A.S.; Leof, E.B.; Shipley, G.D.; Moses, H.L.; Growth factors and cancer. Cancer Res. 1986, 46, 10151029.

25. Witsch, E.; Sela, M.; Yarden, Y. Roles for growth factors in cancer progression. Physiology (Bethesda). 2010, 25, 85-101.

26. Sporn, M.B.; Roberts, A.B. Autocrine growth factors and cancer. Nature. 1985, 313, 745-747.

27. Soussi, T. p53 alterations in human cancer: more questions than answers. Oncogene. 2007, 26, 2145-2156.

28. Scott, S.H.; Bahnson, B.J. Senescence Marker Protein 30: Functional and Structural Insights to its Unknown Physiological Function. Biomol Concepts. 2011, 2, 469-480.

29. Mitchell, J.A.; Shynlova, O.; Langille, B.L.; Lye, S.J. Mechanical stretch and progesterone differentially regulate activator protein-1 transcription factors in primary rat myometrial smooth muscle cells. Am J Physiol Endocrinol Metab. 2014, 287, 439-445.

30. Palmberg, L.; Thyberg, J. Uterine smooth muscle cells in primary culture. Alterations in fine structure, cytoskeletal organization and growth characteristics. Cell Tissue Res. 1986, 246, 253-262. 